\title{
Evaluation of in vitro corrosion resistance and in vivo osseointegration properties of a FeMnSiCa alloy as potential degradable implant biomaterial
}

Lucia Carmen Trincă ${ }^{1}$, Liviu Burtan, ${ }^{2, *}$, Daniel Mareci ${ }^{3,+}$, Bibiana M.

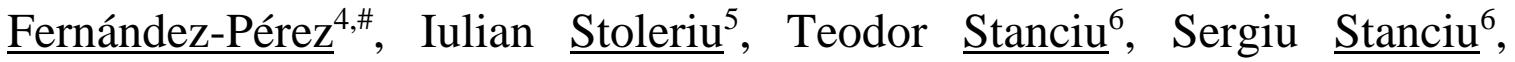
Carmen $\underline{\text { Solcan }}^{7}$, Javier Izquierdo ${ }^{4,8}$, Ricardo M. $\underline{\text { Souto }}^{4,8}, *$

${ }^{1}$ Exact Sciences Department, "Ion Ionescu de la Brad" University of Agricultural Sciences and Veterinary Medicine, Faculty of Horticulture, Str. Aleea M. Sadoveanu, no. 3, 700490, Iasi, Romania, lctrinca@uaiasi.ro

2 Clinics Department, "Ion Ionescu de la Brad" University of Agricultural Sciences and Veterinary Medicine, Faculty of Veterinary Medicine, Str. Aleea M. Sadoveanu, no. 8, 700489, Iasi, Romania, blmv2018@yahoo.com

3 Department of Chemical Engineering, Technical University “Gheorghe Asachi” of Iasi, Faculty of Chemical Engineering and Environmental Protection, D. Mangeron, Iasi, 700050, Romania, danmareci@yahoo.com

4 Department of Chemistry, Universidad de La Laguna, Avda. Astrofísico Francisco Sánchez s/n, E-38200 La Laguna (Tenerife, Canary Islands), Spain

${ }^{5}$ Faculty of Mathematics, "Alexandru Ioan Cuza" University of Iasi, Bd. Carol I, No. 11, 700506 Iasi, Romania, stoleriu@yahoo.com

6 Faculty of Materials Science and Engineering, "Gheorghe Asachi" Technical University of Iasi, Str. Prof. dr. doc. Dimitrie Mangeron, 67, 70005, Iasi, Romania, teddystanciutb@gmail.com, sergiustanciu@yahoo.com

${ }^{7}$ Preclinics Department,"Ion Ionescu de la Brad" University of Agricultural Sciences and Veterinary Medicine, Faculty of Veterinary Medicine, Str. Aleea M. Sadoveanu, no. 8, 700489, Iasi, Romania, carmensolcan@yahoo.com

${ }^{8}$ Institute of Material Science and Nanotechnology, Universidad de La Laguna, P.O. Box 456, E-38200 La Laguna (Tenerife, Canary Islands), Spain, jizquier@ull.edu.es, rsouto@ull.edu.es,

\# Current address: School of Engineering Science in Chemistry, Biotechnology and Health, Royal Institute of Technology, Teknikringen 30, 10044 Stockholm, Sweden, bibiana@kth.se

† Deceased on January 8, 2017.

Corresponding authors:

Ricardo M. Souto: rsouto@ull.es

Liviu Burtan: blmv2018@yahoo.com 


\begin{abstract}
In vitro electrochemical characterization and in vivo implantation in an animal model were employed to evaluate the degradation behavior and the biological activity of FeMnSi and FeMnSiCa alloys obtained using UltraCast (Ar atmosphere) melting. Electrochemical characterization was based on open circuit potential measurement, electrochemical impedance spectroscopy and potentiodynamic polarization techniques while the alloys were immersed in Ringer's solution at $37^{\circ} \mathrm{C}$ for 7 days. Higher corrosion rates were measured for the Ca-containing material, resulting from inefficient passivation of the metal surface by oxy-hydroxide products. In vivo osseointegration was investigated on a tibia implant model in rabbits by referring to a standard control (AISI 316L) stainless steel using standard biochemical, histological and radiological methods of investigation. Changes in the biochemical parameters were related to the main stages of the bone fracture repair, whereas implantation of the alloys in rabbit's tibia provided the necessary mechanical support to the injured bone area and facilitated the growth of the newly connective tissue, as well as osteoid formation and mineralization, as revealed by computed tomography reconstructed images and validated by the bone morphometric indices. The present study highlighted that the FeMnSiCa alloy promotes better osteoinduction and osseointegration processes when compared to the base FeMnSi alloy or with AISI 316L, and in vivo degradation rates correlate well with corrosion resistance measurements in Ringer's solution.
\end{abstract}

Keywords: biodegradable implant materials; surface characterization; corrosion resistance; FeMnSiCa alloy; FeMnSi alloy; osseointegration. 


\section{Abbreviations:}

ALP: alkaline phosphatase

BV/TV: bone volume/total volume ratio

$\mathrm{Ca}^{2+}$ : ionic calcium

CT: computed tomography

EDS: Energy dispersive X-ray spectroscopy

EC: equivalent circuit

EIS: Electrochemical impedance spectroscopy

OCP: open circuit or zero current potential

$\mathrm{PO}_{4}{ }^{3-}$ : inorganic phosphate

Tb.h: trabecular thickness

Tb.Sp: trabecular space

SEM: Scanning electron microscopy 


\section{Introduction}

An ideal biodegradable material should be biocompatible with bone tissue, sufficiently porous to stimulate bone induction, with a stable structure during the healing period to ensure osseointegration, but easily resorbable thereafter to leave no harmful traces in the body [1,2]. Iron-based biodegradable materials are attracting interest because in vivo tests have shown that pure iron implants do not show toxicity effects, neither inflammation processes [3]. In addition, iron-based alloys have an excellent mechanical behavior, in addition to being inexpensive likewise stainless steel [4-8]. The strength and rate of degradation rate of pure Fe increases in alloys that combine Mn with Fe [9-12]. On the other hand, Si is an essential trace element for bone development that is involved in osteogenesis and collagen synthesis [13-17]. The addition of Ca can increase the bioactivity of the basic alloy, either by enhancing interactions at the implant-bone interface and by promoting the activation of osteoblasts [18-24].

The main hindrance for iron-based alloys to be employed for the manufacturing of biodegradable implants is the slow degradation rate of these materials [4]. Indeed, Fe-Mn alloys exhibit degradation rates at least one order of magnitude smaller than magnesiumbased alloys $[15,19,25]$. Therefore, work in progress focuses on developing new iron-based materials with lower corrosion resistance and higher degradation rates.

In this work, the microalloying of an Fe10Mn6Si alloy by adding 1 wt.\% Ca was investigated as a candidate material for bone implants by performing in vitro corrosion resistance tests as well as in vivo tests, and characterizing the surface of the samples after implantation. The main objective of this work was to evaluate and compare the degradation rates, corrosion mechanisms and osseointegration processes of the Fe10Mn6Si alloy with 1\% added $\mathrm{Ca}$ (which will be named hereafter FeMnSiCa), with those of the unmodified Fe10Mn6Si (which will be named hereafter FeMnSi). Electrochemical characterization was performed in a simulated body fluid as corrosive environment, whereas in vivo tests were conducted in rabbit tibiae through cross-examined biochemical, histological and computed tomography (CT) investigations. The surface morphology and composition of the FeMnSiCa and FeMnSi specimens were investigated by scanning electron microscopy (SEM) and energy dispersive X-ray spectroscopy (EDS). In addition, the relationship 
between in vitro corrosion resistance characterization and in vivo performance was also discussed in order to evaluate the potential of FeMnSiCa alloys for biomedical application.

\section{Materials and Methods}

\subsection{Materials}

The master Fe10Mn6Si alloy was produced by melting the high-purity metallic elements (i.e., Fe 99.99\%, Mn 99.98\% and Si 99.9\%) in an electric arc furnace (RAV MRF ABJ_900, Allenstown, NY, USA). Details on the fabrication, as well as the structural and surface characterization of the as cast alloy, have been reported elsewhere $[16,26]$. Ca was added within 1 wt.\% by the use of a vacuum induction furnace (UltraCast, Ronkonkoma, NY, USA) in a ceramic crucible [23]. The casted material was melted and annealed in a fluid bed of sand at $1050{ }^{\circ} \mathrm{C}$ for $300 \mathrm{~min}$, then cooled along with the sand in which it was heated to obtain a homogenous solid solution and thus reducing the heating fragility induced by the hot deformation process.

\subsection{Surface characterization}

The morphological characterization of the implanted surfaces was carried out by scanning electron microscopy (SEM, model Vega II LMH provided with a SE detector, Tescan, Brno, Czech Republic), while the chemical analysis of the surface of the material was performed by EDS (model XFlash with PB-ZAF Esprit software, Bruker, Billerica, MA, USA). MATLAB software [27] was employed for 2D- and 3D-reconstruction of the images of the plot surface profiles.

\subsection{In vitro electrochemical characterization}

FeMnSi and FeMnSiCa ingots were cut into small strips and mounted into a resin sleeve (Epofix kit, Struers, Ballerup, Denmark) to offer a flat surface for electrochemical tests, while the metal was allowed to protrude at the rear of the sleeve for electrical connection. The exposed areas were determined under microscope, namely $0.23 \mathrm{~cm}^{2}$ for FeMnSi, and $0.35 \mathrm{~cm}^{2}$ for the FeMnSiCa samples, respectively. The samples were abraded with silicon carbide paper down to 4000 grit, thoroughly rinsed with Millipore deionized water (resistivity, $18 \mathrm{M} \Omega \mathrm{cm}$ ), and sonicated in ethanol for 15 minutes. Electrochemical 
tests were performed in Ringer's solution in order to simulate the corrosive aggressiveness of the physiological media. Ringer's solution was prepared from analytical grade reagents and Millipore deionized water. The composition of the Ringer's solution was $8.5 \mathrm{~g} / \mathrm{L} \mathrm{NaCl}$, $0.40 \mathrm{~g} / \mathrm{L} \mathrm{KCl}$ and $0.34 \mathrm{~g} / \mathrm{L} \mathrm{CaCl}_{2} \cdot 2 \mathrm{H}_{2} \mathrm{O}$. The temperature of the electrochemical cell was maintained at $37 \pm 1^{\circ} \mathrm{C}$.

The alloy sample surrounded by the resin sleeve was placed upwards in the electrochemical cell, with a platinum grid and a saturated calomel electrode (SCE) serving as auxiliary and reference electrode, respectively. The electrochemical cell was placed inside a Faraday cage. Measurements were conducted using an EG\&G Princeton Applied Research model 2263 potentiostat/galvanostat (AMETEK, Berwyn, PA, USA). Samples were initially left at their open circuit potential (OCP) for 1 hour in order to develop a quasi-stable potential value. Electrochemical impedance spectroscopy (EIS) measurements were performed with the samples still unbiased at their open circuit potential in the test electrolyte, after 1 hour, 1 day, and 1 week of immersion in Ringer's solution at $37^{\circ} \mathrm{C}$. EIS data were conducted by applying a sine wave perturbation at frequencies between $20 \mathrm{kHz}$ and $1 \mathrm{mHz}$, with amplitude of $\pm 10 \mathrm{mV}$. The data quality acquisition was established in 15 cycles at each frequency, thus providing good signal-to-noise ratios at all frequencies. The impedance spectra were modelled in terms of an equivalent circuit by using Yeum's ZSimpWin 2.00 software to [28]. Finally, linear polarization tests were performed after 1 week of immersion, namely Tafel analysis, within the potential range between -200 and +200 $\mathrm{mV}$ vs. OCP, at scan rate $1 \mathrm{mV} / \mathrm{s}$.

\subsection{Evaluation of in vivo osseointegration}

Three groups of three rabbits each (3 months of age, approximately $1.8 \mathrm{~kg}$ ), received by surgery on the tibial crest (see Figure 1) an implanted specimen of parallelepiped shape $(25 \mathrm{~mm} \times 2.5 \mathrm{~mm} \times 0.5 \mathrm{~mm})$, either of the new alloys under investigation (i.e., FeMnSiCa and FeMnSi) or a control (AISI 316L stainless steel).

During the experiment, the animals were housed with free access to food and water in accordance with the ISO10993-2:2006 standard on animal welfare [29]. The experimental model was carried out for four weeks (28 days). The body response of the implanted animal was followed, in the first stage, by clinical observations and biochemical 
analyses of blood samples collected every 7 days. In a second stage, the body response was further controlled by computed tomography and histopathological investigations on bone samples collected at the end of the experimental period.

\subsubsection{Biochemical analysis}

Blood samples were collected under anesthetic conditions, every seven days after the implantation procedure. The analyses were performed at the Clinical Biochemical Laboratory (Faculty of Veterinary Medicine, Iasi). The blood serum was separated by centrifugation and the inorganic phosphate $\left(\mathrm{PO}_{4}{ }^{3-}\right)$, the ionic calcium $\left(\mathrm{Ca}^{2+}\right)$, the alkaline phospatase (ALP) and total proteins (TP) were determined spectrophotometrically [19].

\subsubsection{Histological analysis}

The callus along with the normal bone was collected from the site of the fracture. The samples were cut into small pieces and stored in 10\% formalin solution for three days, demineralized with $10 \%$ trichloroacetic acid, dehydrated in ascending grades of alcohol and finally embedded in paraffin. Sections five to six micrometers thick were cut from the area near the defect site, and prepared for staining with hematoxylin and eosin (H\&E staining method) for histological studies [15]. The stained sections were examined under a light microscope using $100 \times$ to $1000 \times$ magnifications.

\subsubsection{CT analysis}

A high-resolution CT system (X-ray CT, Siemens Somatom, Balance, Erlangen, Germany) was used to evaluate the microstructure of each left hind limb of the rabbit, with a scanning resolution of $20 \mu \mathrm{m} / \mathrm{slice}$. 3-D images were reconstructed based on the acquired 2-D image sequences, using the Syngo Viewer image software, Version 2.21. Trabecular bone parameters, including bone volume per tissue volume (BV/TV), trabecular thickness (Tb.Th) and trabecular separation (Tb.Sp) were quantified using ImageJ and BoneJ software [30]. The region of interest was defined as a rectangle circumscribing the surface of the implant (embedding the implant surface tangentially) to which $1000 \mu \mathrm{m}$ was added in both length and width. 


\subsubsection{Statistical analysis}

Statistical analyses were performed using IBM SPSS Statistics (IBM Corp. Released 2012 IBM SPSS Statistics for Windows, Version 21.0; IBM Corp, Armonk, NY, USA) [31]. For in vivo results, the differences between the experimental groups were examined using the Mann-Whitney $U$ Test, and the one-way analysis of variance (ANOVA), with a $p<0.05$ considered a statistically significant difference.

\section{Results and discussion}

\subsection{In vitro electrochemical characterization}

\subsubsection{Open circuit potential}

The evolution of the open circuit potential (OCP) following immersion in Ringer's solution is shown in Figure 2. A shift of OCP in the negative direction indicates the activation of metal dissolution in the aqueous environment immediately at short exposure times. At longer times, the shift of the OCP values to more negative potentials occurs at a slower rate, indicating an almost stationary regime. Therefore, electrochemical tests were initiated after 1-hour exposure to the simulated body fluid. As it can be seen in Figure 2, the OCP of the FeMnSi alloy shifted to the negative direction of potential with the addition of Ca, by approximately $120 \mathrm{mV}$, probing the latter to be a more electrochemically active material towards corrosion.

\subsubsection{EIS measurements and equivalent circuit analysis}

EIS measurements were performed after 1 hour, 1 day and 1 week of immersion in Ringer's solution, producing the impedance plots presented in Figure 3 for the FeMnSi and the FeMnSiCa alloys. Impedance data are displayed as both Nyquist (real vs. minus the imaginary part of the impedance), and Bode-amplitude and Bode-phase diagrams (modulus $(|Z|)$ and phase angle $(\Phi)$ vs. frequency (f), respectively). The best correlation between experimental and fitted data were obtained using the equivalent circuit depicted in Figure $4 \mathrm{a}$, leading to $\chi^{2}$ values in the $10^{-3}$ to $10^{-4}$ range, and the corresponding impedance parameters are listed in Table 1 . The capacitive components were better described using a 
constant phase element, $Q$, instead of a pure capacitance, whose impedance is determined using [32]:

$$
Z_{Q}=(j \omega)^{-n} Q^{-1}
$$

where $n$ may vary from 0 (pure resistance) to 1 (pure capacitor), in which case $Q$ would be equal to the capacity of the capacitor; $\omega$ is the angular frequency; and $j$ is the imaginary number $\left(j^{2}=-1\right)$. In both equivalent circuits, $R_{s}$ represents the resistance of the solution and typically does not depend on the substrate surface.

The FeMnSi and FeMnSiCa alloys immersed in Ringer's solution behaved as a physicochemical system with two time constants (i.e., two combinations in parallel of a resistor and a pseudo-capacitor). The two time constants could be easily distinguished from the Bode-phase plot even as early as 1-hour immersion. This feature reflects the presence of two interfaces, namely metal oxide-electrolyte and metal-metal oxide, represented by the $R_{1} Q_{1}$ and $R_{2} Q_{2}$ pairs of elements, respectively [33]. The constant phase elements of the metal oxides have an intermediate behaviour between those corresponding to a capacitor and a resistor, as evidenced by $n$ values close to 0.5 . This reflects the presence of a leaking double layer which, according to the $Q$ values, progressively increases in capacitance upon exposure to the electrolyte. At the same time, the metal-metal oxide interface accounts for a larger resistance to the charge transfer process (cf. $R_{2}$ in Table 1 ) and more capacitive behaviour.

Although the electrochemical impedance behaviour of the two alloys showed some similarities as to be described by the same equivalent circuit, closer inspection of the spectra depicted in Figure 3 allows distinguishing a major difference in regards to the time evolution of the system. That is, the corrosion activity of the FeMnSi decreases abruptly upon immersion in the electrolyte due to passivation of the surface by the formation of an oxy-hydroxide layer sufficient to slow down the metal dissolution rate from the alloy, resulting in 10-fold increase of the impedance modulus in the low frequency range as observed in Figure 3b, layer that was already developed after 1 day exposure, whereas it aged slowly for longer exposures (see Figures 3a and 3b). Nevertheless, the layer formed on the surface of the alloy was not an efficient dielectric barrier layer because it was unable to attain a frequency range with capacitive behaviour in the Bode-phase diagrams shown 
in Figure 3c, but its resistance was sufficient to provide some degree of passivation to this alloy in the test electrolyte. In addition, the magnitude of the corresponding pseudocapacitance values listed in Table 1 is characteristic for a layer of precipitated corrosion products instead of a compact oxide barrier film. Altogether, the metal can be regarded to degrade spontaneously in vitro, although at a slow rate, due to the precipitation of oxyhydroxide compounds on the surface.

In the case of the alloy containing Ca, the EIS diagrams depicted in Figure 3d-f clearly show a trend to decrease the sample impedance shortly after exposure to the test electrolyte, that is observed from the reduction of the diameter of the semicircle in the Nyquist plot (cf. Figure 3d), and from the decrease of the impedance values in the Bode plot in the low frequency range (Figure 3e). Thus, impedance data show a progressive activation of the sample during immersion in Ringer's solution, thereby accelerating the corrosion rate when exposed to this simulated body fluid. In fact, the slower corrosion rates for the Ca-modified alloy are observed only at the beginning of the experiment (cf. Figure 3d), when the corrosion rate was close to that exhibited by FeMnSi (Figure 3a). In addition, the decrease of the electrochemical impedance for longer exposures mainly occurred in the low frequency range, which accounts for the electrochemical characteristics of the oxyhydroxide layer developed on the metal. Although slightly higher values for the impedance modulus in the low frequency range were registered after 1-week exposure to the physiological solution, this effect was accompanied by the observation of higher dissolution rates at the metal-metal oxide interface in the high frequency range. This feature supports that although some precipitation process may also occur on FeMnSiCa sample at longer exposures, it is insufficient to hinder metal dissolution. Therefore, in vitro electrochemical characterization is consistent with a more biodegradable material than the FeMnSi alloy considered as reference.

It is also important to observe that the total resistance of the FeMnSiCa alloy is more than one order of magnitude smaller than for the FeMnSi alloy at the end of the in vitro tests (e.g., 0.35 and $72.9 \mathrm{k} \Omega \mathrm{cm}^{2}$, respectively). More interestingly, the inspection of Figure $4 \mathrm{~b}$ leads to observed that the $R_{2}$ component accounts totally for the observed change in the total resistance. This fact indicates that the addition of Ca to the FeMnSi alloy, although as minor constituent, is very effective in preventing or at least reducing the 
precipitation of the oxy-hydroxide layer on the corroding metal in Ringer's solution, thus preventing its passivation.

\subsubsection{Tafel analysis}

Linear polarization measurements were performed at the end of the in vitro tests, immediately after recording the EIS spectra for 1-week exposure. The corresponding Tafel plots are given in Figure 5 depicted as semi-logarithmic diagrams, and the relevant electrochemical parameters derived from their analysis are listed in Table 2. The behaviour of the two alloys differed significantly after 7 days of immersion, leading to a more positive OCP value only in the case of the base FeMnSi alloy, which is an indication of the development of an oxy-hydroxide layer on the surface of this material. Conversely, the OCP value determined for the FeMnSiCa alloy is slightly more negative than the value attained at the beginning of the experiments (cf. Figure 2). This is an indication of the inability of the modified alloy to achieve a passive condition. Although the corrosion current densities obtained from the corresponding Tafel lines are similar for both metals, a current plateau (characteristic of the passivation process) could be found in the anodic branch for the FeMnSi alloy, which supports a bigger degradation rate for the alloy modified by adding $\mathrm{Ca}$.

\subsection{Evaluation of in vivo osseointegration}

\subsubsection{Dynamics of total calcium, inorganic phosphate and alkaline phosphatase activity} mean values from the rabbit experimental model with tibial implant

Figure 6a shows that the alkaline phosphatase activity exhibited statistically significant variations $(p<0.05)$ at 7,14 and 21 days, and statistically insignificant variations at 28 day post implantation for all considered groups. This fact reveals a normal bone fracture healing process [34]. By referring to the normal state (day 0), the statistically significant variations $(p<0.05)$ of the alkaline phosphatase activity in the case of FeMnSi and FeMnSiCa groups outline an intensified process of osteogenesis through the activation of osteoblasts $[15,19]$.

The variations of the biochemical parameters were associated and correlated statistically, thus pointing out the local processes involved in the repair of bone fractures. 
Although the values of inorganic phosphatemia and alkaline phosphatase activity recorded after seven days from implantation remained approximately normal, those recorded at fourteen days were significantly lower, which is interpreted as a somewhat delayed metabolic disturbance induced by the surgical trauma [35-42]. On day 21 compared to day 14 , the statistically significant increase $(p<0.05)$ in blood calcium and inorganic phosphate values was moderately correlated $\left(R^{2}=0.523\right)$ with increased phosphatase activity alkaline due to mobilization of osteoblasts [43-45]. In addition, the statistically significant hypophosphatemia $(p<0.05)$ recorded between 21-28 days was strongly correlated $\left(R^{2}=\right.$ 0.973) with hypocalcemia, which was determined by the transformation of the osteoblasts into osteoclasts once with their entrapment by the extracellular matrix of calcium phosphate [46-49].

\subsubsection{Histological evaluation of the bone-implant interface}

No inflammatory effects or signs of rejection were observed [50-52] for any histological bone sample from any of the three groups of rabbits.

The new cancellous bone in the case of the control group of rabbits imaged in Figure 7a-b was characterized by presenting small areoles with a small number of cells in the periphery, while the larger areoles showed hematogenous bone marrow with specific cells at different stages of evolution. In the periphery of the bone areoles, osteoblasts arranged in a row in the bone bays, few osteocytes in the lagoons and also osteoprogenitor cells with fusiform aspect were observed.

In the case of FeMnSi group of rabbits, Figure 7c-d shows that the new cancellous bone contained small peripheral areoles with a reduced number of cells. The next layer showed larger areoles with hematogenic bone marrow. In the larger areoles, osteoblasts can be observed, as adherent to the bone bays and arranged similarly to an epithelium [53]. The osteocytes of the lacunas are larger, with a vacuolar appearance. The hematogenic bone marrow was dense. The periosteum was evident, with proliferating osteoprogenitor cells.

The new cancellous bone in the case of the FeMnSiCa group of rabbits (see Figure 7e-f), showed bone bays with different diameters, colored differently either in light shades of pink for pro-ossein or, in dark shades of pink for the mature bone impregnated with 
mineralized salts. Active and bigger osteoblasts, with many large extensions, arranged in 2 to 3 rows were attached to the bone bays. Large osteocytes could be seen in some bone bays, while other bone bays showed a vacuolar appearance. The greater number of osteoblasts sustained higher osseointegration in the case of FeMnSiCa group when compared with FeMnSi group [54]. The periosteum was evident in the proliferation area of the osteoprogenitor cells, which will leave into the peripheral bone areolas. In the peripheral area, proliferative differentiation tissue was observed in areolas and in immature bays, which support a greater regeneration of bone tissue [55] in the case of the FeMnSiCa rabbit group.

\subsubsection{CT characterization}

The objective of the computed tomography investigation was to evaluate the integrity of the implant surface, as well as the microstructure of the newly formed bone tissue deposited on the surface of the implant, together with the intensity of various processes involved in the repair of the bone fracture [56,57]. The reconstructed 2D images (transversal section) of the implant surfaces given in Figure 8 showed that integrity of the implant surface was affected in the largest proportion by the biodegradation process in the case of the FeMnSiCa implant, and in the smallest proportion for the FeMnSi implant.

The reconstructed 3D images of the bone-implant interface (Figure 8) highlighted that one month after the implantation surgery, the FeMnSiCa implant was covered in greater proportion with a thick layer of the newly formed bone. In addition, the ratio of bone volume per volume unit of tissue as shown in Figure 9, was highest in the case of FeMnSiCa group, being statistically significant $(p<0.005)$ compared to the FeMnSi or the control groups.

The values of trabecular thickness (Tb.Th.) showed the highest values in the case of the FeMnSiCa implant, without registering statistically significant differences $(p>0.05)$ for any of the experimental groups. At the same time, in comparison with the FeMnSi group, the statistically significant decreased values $(p<0.05)$ of the trabecular spaces (Tb.Sp.) in the newly formed bone revealed a higher osseointegration process [58,59] for the FeMnSiCa implant. 


\subsection{Surface characterization of the implanted specimens}

Figure 10a-b shows the morphology of the alloy surfaces (i.e., (a) FeMnSi and (b) FeMnSiCa) after implantation and subsequent cleaning by ultrasonication by using 2D- and 3D-reconstructed SEM maps. Image analysis of the just harvested samples revealed the formation of consistent deposits on the surfaces of both samples during the implantation period, and such a deposition process was more extensive on the FeMnSiCa sample. According to our previous report [15], on the surface of the implanted specimen, initially will appear $\mathrm{Fe}, \mathrm{Mn}, \mathrm{Si}, \mathrm{Ca}$ and $\mathrm{Mg}$ oxides, which will form hydroxides when interacting with the internal hydrophilic environment of the body. In addition, these oxyhydroxides can further react with various ionic components of the blood or bone tissue to form salts, which either will be taken up and transported by the blood to other tissues, or once nucleation centers were created, will be deposited on the surface of the implant together with other salts of $\mathrm{Na}, \mathrm{Mg}$, or $\mathrm{Ca}$ and $\mathrm{P}$. The ratio between the stability and the reactivity of the resulting oxy-hydroxides and salts will influence the intensity of the biodegradation processes and the type of corrosion manifested by the implanted alloy in the bone tissue $[1,2]$.

The cleaning by ultrasonication of the implanted samples revealed a larger fraction of the surface area affected by general corrosion in the case of the FeMnSiCa sample (see Figure 10b) than for the master FeMnSi alloy (Figure 10a). This feature probes that Ca addition induced an increased reactivity of the FeMnSiCa alloy by enhancing interactions at the bone-implant interface. A detailed analysis of the surface topography indicates that on the background of an average roughness, the denser closely spaced irregularities (shown by the plot surface profiles included in Figure 10c-d), are the main indicators that highlight the increase in surface biodegradability through increased reactivity induced by the addition of $\mathrm{Ca}$ in the FeMnSiCa alloy. Further analysis of the 2D- and 3D-reconstructed SEM images allowed that also porosity evaluations to be conducted along the red lines drawn on the micrographs of Figure 10c-d, and the obtained data are summarized in Table 3. Larger values for the 3D specific surface pores and porosity were found for the FeMnSiCa specimen (cf. Figure 10e-f), a feature that can be regarded as a major sign of an extensive general corrosion of FeMnSiCa alloy. 
Given that the initial thickness of the FeMnSi implant was $500 \mu \mathrm{m}$, while the remaining thickness after extraction and ultrasonic cleaning of the implant was $490 \mu \mathrm{m}$ (determined as the average of three separate measurements), then around $10 \mu \mathrm{m}$ of metallic material was lost during implantation period. By considering that degradation rates should be approximately the same at each end of the sample, we can consider that $5 \mu \mathrm{m}$ were lost from each side. Analogously, the variation of thickness of the FeMnSiCa implant resulting from implantation can be determined by comparing the initial value of $450 \mu \mathrm{m}$ with that observed after extraction and ultrasonic cleaning as being $400 \mu \mathrm{m}$ (average of three measurements). Thus, approximately $50 \mu \mathrm{m}$ of metallic material was lost during implantation period, with $25 \mu \mathrm{m}$ for each part. Assuming an ideal constant degradation rate to operate during the implantation period, complete degradation of the implanted samples would require 50 months for the FeMnSi implant and only 9 months for the FeMnSiCa implant. Although the complexity of the degradation process would require further elaborated analyses [60-62] to establish the actual period of time needed for the degradation process of both specimens, a rough estimate of ca. 6-fold higher degradation rates for the Ca-containing alloy can be estimated. This estimate correlates very well with the 5 -fold increase derived from the in vitro corrosion tests as described in Section 3.1.2.

The retrieved specimens were further analyzed by EDS to monitor changes in the composition distribution of the main constituent elements of the alloys over the implantation period. For the sake of reproducibility, EDS analysis was performed at three representative locations over the investigated surfaces, and the main observations are listed in Tables 4 and 5 for FeMnSi and the FeMnSiCa alloys, respectively. It is interesting to observe that the same specific signals were observed for both specimens either as retrieved or after ultrasonic cleaning: two energy lines for Fe (with $k_{a}$ peak being much bigger then $k$ beak), two energy lines for Mn (with $k$ beak being much bigger then $k_{a}$ peak), and one energy line for Si. The major difference aimed the Mn peak $\left(k_{\mathrm{a}}\right)$, which was more intense and shifted to lower Energy-keV values in the case of the FeMnSiCa specimen. The lack of Ca signal from the implanted specimen after ultrasonic cleaning reveals that calcium was quantitatively lost from the metallic material surface. This feature can be attributed to the transformation of calcium from the alloy surface into ionic calcium $\left(\mathrm{Ca}^{2+}\right)$ in the hydrophilic environment of the internal body. These ionic species will 
subsequently diffuse from the corrosion layer, being able to react with $\left(\mathrm{PO}_{4}\right)^{3-}$ or $\left(\mathrm{CO}_{3}\right)^{2-}$ anions from the blood/bone tissue in order to form calcium phosphate and carbonate [15].

Both implanted specimens, prior to ultrasonic cleaning (see areas 1-3 in Tables 4 and 5) showed rather high quantities of oxides, as well as $\mathrm{C}$ and Ca-P based compounds, but also some K and S derivatives occurred, either being new species formed and deposited on the metallic surface, or biological tissue traces. After ultrasonic cleaning of both implanted specimens, the areas 4-6 showed that large quantities of Si oxides, some amounts of Fe and Mn oxides together with C-based compounds as well as various salts were removed. Thus, more than $80 \%$ of the deposited compounds were detached from the surface, such that, only in some areas, it remained some stable oxides and small quantities of calcium-phosphorus based compounds. The Mn percentage close to the initial values and the higher quantity of Si from the specimens cleaned by ultrasonication (i.e., areas 4-6) may be explained (in good accordance with the kinetics of Si oxides formation and with the passing rates of $\mathrm{Fe}, \mathrm{Mn}$, and $\mathrm{Si}$ compounds into solution), by the continuous transfer of the oxides of these elements into the hydrophilic environment of the internal body, either being blood/ bone tissue. These results outline that Mn compounds from the implanted alloy are more prone to corrosion than Si compounds due to their higher electrochemical potential that will induce an increased reactivity. In order to preserve the shape memory properties of the FeMnSi specimen [63-65], the added content of Ca in the alloy was kept very low (under 1\%). After implantation, the low Ca concentration was reduced even more, due to its bigger reactivity in the bone tissue environment. Thus, the EDS investigation of the implanted and cleaned sample showing no signal for $\mathrm{Ca}$ (that was below the detection limit of $0.05 \mathrm{wt} . \%$ ) is in agreement with previous reports describing the role of calcium addition for increasing the degradation rate of the FeMnSi alloy $[16,23,66]$.

Additionally, the differences in concentration between areas 1 and 2 (cf. Tables 4 and 5) outlined the heterogeneous composition of the degradation layers developed on the surface of the alloy. In the case of area 3 (Tables 4-5), the oxide layer is not compact, thus leading to the observation of larger signals for the main element constituents (Fe,Mn,Si) of the alloy. 


\section{Conclusions}

This work showed the ability of Ca-containing FeMnSi alloys to degrade at higher corrosion rates while simultaneously promoting improved osteoinduction and osseointegration processes compared to the base FeMnSi alloy or to standard AISI 316L stainless steel.

In vitro electrochemical testing of the FeMnSi and FeMnSiCa alloys in Ringer's simulated body fluid evidenced increased corrosion rates for the latter, which can be acceptable for the fabrication of biodegradable implants. More than one order of magnitude decrease of the total resistance of the material occurs with small additions of Ca to a FeMnSi master alloy.

In vivo model animal tests consisting in the implantation of the FeMnSi and FeMnSiCa alloys in the rabbits' tibia provided the necessary mechanical support to the injured bone area but also facilitated the growth of the newly connective tissue, as well as the osteoid formation and initiation of the mineralization, as revealed by the CT reconstructed images and validated by the bone morphometric indices. During this experimental period, the changes monitored in biochemical parameters were related with the main stages of the bone fracture repair.

After 28 day implantation period in the rabbit's tibia, the surfaces of both FeMnSi and FeMnSiCa specimens exhibited signs of a general corrosion process with a larger extent of the degradation process in the case of the FeMnSiCa specimen.

The estimations of increased degradation rates for the new FeMnSiCa alloy with regards to the master FeMnSi alloy from in vitro corrosion tests agreed well with those derived from in vivo observations, thus demonstrating the powerful experimental combination offered by these two technical approaches for the accelerated testing and the characterization of new potential biodegradable materials with potential implant application.

\section{Acknowledgements:}

This work was supported partially by the Romanian National Authority for Scientific Research (CNCS-UEFISCDI, Bucharest, Romania) under project No. PN-II-IDPCE-2011- 
3-0218, and by the Spanish Ministry of Economy and Competitiveness (MINECO, Madrid, Spain) and the European Regional Development Fund (Brussels, Belgium) under project No. CTQ2016-80522-P.

\section{References}

[1] Y.F. Zheng, X.N. Gu, F. Witte, Biodegradable metals, Mater. Sci. Eng. R 77 (2014) 1-34. doi:10.1016/J.MSER.2014.01.001.

[2] M. Prakasam, J. Locs, K. Salma-Ancane, D. Loca, A. Largeteau, L. Berzina-Cimdina, Biodegradable materials and metallic implants - A review, J. Funct. Biomater. 8 (2017) 44, 15 pages; doi:10.3390/jfb8040044.

[3] B. Wegener, B. Sievers, S. Utzschneider, P. Müller, V. Jansson, S. Rößler, B. Nies, G. Stephani, B. Kieback, P. Quadbeck, Microstructure, cytotoxicity and corrosion of powder-metallurgical iron alloys for biodegradable bone replacement materials,

Mater. Sci. Eng. B $176 \quad$ (2011) 1789-1796; doi: https://doi.org/10.1016/j.mseb.2011.04.017.

[4] M. Schinhammer, A.C. Hänzi, J.F. Löffler, P.J. Uggowitzer, Design strategy for biodegradable Fe-based alloys for medical applications, Acta Biomater. 6 (2010) 1705-1713. doi:10.1016/j.actbio.2009.07.039.

[5] M.F. Ulum, A. Arafat, D. Noviana, A.H. Yusop, A.K. Nasution, M.R. Abdul Kadir, H. Hermawan, In vitro and in vivo degradation evaluation of novel iron-bioceramic composites for bone implant applications, Mater. Sci. Eng. C 36 (2014) 336-344. doi:10.1016/j.msec.2013.12.022.

[6] J. He, F.L. He, D.W. Li, Y.L. Liu, Y.Y. Liu, Y.J. Ye, D.C. Yin, Advances in Fe-based biodegradable metallic materials, RSC Adv. 6 (2016) 112819-112838. doi:10.1039/C6RA20594A.

[7] M. Elbadawi, M. Shbeh, High strength yttria-reinforced HA scaffolds fabricated via honeycomb ceramic extrusion, J. Mech. Behav. Biomed. Mater. 77 (2018) 422-433. doi:10.1016/j.jmbbm.2017.10.009.

[8] R. Gorejová, L. Haverová, R. Oriňaková, A. Oriňak, M. Oriňak, Recent advancements in Fe-based biodegradable materials for bone repair, J. Mat. Sci. 54 (2019) 1913-1947. doi:10.1007/s10853-018-3011-z. 
[9] H. Hermawan, D. Dubé, D. Mantovani, Degradable metallic biomaterials: Design and development of Fe-Mn alloys for stents, J. Biomed. Mater. Res. A 93 (2010) 111. doi:10.1002/jbm.a.32224.

[10] H. Li, Y. Zheng, L. Qin, Progress of biodegradable metals, Prog. Nat. Sci. Mater. Int. 24 (2014) 414-422. doi:10.1016/j.pnsc.2014.08.014.

[11] T. Kraus, F. Moszner, S. Fischerauer, M. Fiedler, E. Martinelli, J. Eichler, F. Witte, E. Willbold, M. Schinhammer, M. Meischel, P.J. Uggowitzer, J.F. Löffler, A. Weinberg, Biodegradable Fe-based alloys for use in osteosynthesis: Outcome of an in vivo study after 52 weeks, Acta Biomater. 10 (2014) 3346-3353. doi:10.1016/j.actbio.2014.04.007.

[12] M. Heiden, E. Walker, E. Nauman, L. Stanciu, Evolution of novel bioresorbable ironmanganese implant surfaces and their degradation behaviors in vitro, J. Biomed. Mater. Res. A 103 (2015) 185-193. doi:10.1002/jbm.a.35155.

[13] M. Bohner, Silicon-substituted calcium phosphates - A critical view, Biomaterials 30 (2009) 6403-6406. doi:10.1016/j.biomaterials.2009.08.007.

[14] A.F. Khan, M. Saleem, A. Afzal, A. Ali, A. Khan, A.R. Khan, Bioactive behavior of silicon substituted calcium phosphate based bioceramics for bone regeneration, Mater. Sci. Eng. C 35 (2014) 245-252. doi:10.1016/j.msec.2013.11.013.

[15] M. Fântânariu, L.C. Trincă, C. Solcan, A. Trofin, Ș. Strungaru, E.V. Şindilar, G. Plăvan, S. Stanciu, A new Fe-Mn-Si alloplastic biomaterial as bone grafting material: $\begin{array}{llllll}\text { In vivo study, Appl. Surf. } & \text { Sci. } 352 \quad \text { (2015) 129-139. }\end{array}$ doi:10.1016/j.apsusc.2015.04.197.

[16] N. Cimpoeşu, L.C. Trincă, G. Dascălu, S. Stanciu, S.O. Gurlui, D. Mareci, Electrochemical characterization of a new biodegradable FeMnSi alloy coated with hydroxyapatite-zirconia by PLD technique, J. Chem. (2016) Article ID 9520972, 9 pages. doi:10.1155/2016/9520972.

[17] S. Stanciu, A. Ursanu, L.C. Trincă, T.A. Elena, S. Carmen, C. Munteanu, N. Cimpoesu, D. Acatrinei, E.V. Sindilar, T. Stanciu, M. Fântânariu, Study on the biodegradability of FeMnSi alloy, Environ. Eng. Manag. J. 15 (2016) 973-980. doi:10.30638/eemj.2016.106.

[18] R. Oriňáková, A. Oriňák, L.M. Bučková, M. Giretová, L. Medveckỳ, E. Labbanczová, 
M. Kupková, M. Hrubovčáková, K. Koval, Iron based degradable foam structures for potential orthopedic applications, Int. J. Electrochem. Sci. 8 (2013) 12451-12465.

[19] L.C. Trincă, M. Fântânariu, C. Solcan, A.E. Trofin, L. Burtan, D.M. Acatrinei, S. Stanciu, B. Istrate, C. Munteanu, In vivo degradation behavior and biological activity of some new Mg-Ca alloys with concentration's gradient of Si for bone grafts, Appl. Surf. Sci. 352 (2015) 140-150. doi:10.1016/j.apsusc.2015.03.136.

[20] D. Hong, D.T. Chou, O.I. Velikokhatnyi, A. Roy, B. Lee, I. Swink, I. Issaev, H.A. Kuhn, P.N. Kumta, Binder-jetting 3D printing and alloy development of new biodegradable Fe-Mn-Ca/Mg alloys, Acta Biomater. 45 (2016) 375-386. doi:10.1016/j.actbio.2016.08.032.

[21] F. Săndulache, S. Stanciu, N. Cimpoeşu, T. Stanciu, R. Cimpoeşu, A. Enache, R. Baciu, Preliminary results on the surface of a new Fe-based metallic material after “in vivo” maintaining, IOP Conf. Series: Materials Science and Engineering 209 (2017) 012049. doi:10.1088/1757-899X/209/1/012049.

[22] Y. Li, H. Jahr, K. Lietaert, P. Pavanram, A. Yilmaz, L.I. Fockaert, M.A. Leeflang, B. Pouran, Y. Gonzalez-Garcia, H. Weinans, J.M.C. Mol, J. Zhou, A.A. Zadpoor, Additively manufactured biodegradable porous iron, Acta Biomater. 77 (2018) 380393. doi:10.1016/j.actbio.2018.07.011.

[23] N. Cimpoeşu, F. Săndulache, B. Istrate, R. Cimpoeşu, G. Zegan, Electrochemical behavior of biodegradable FeMnSi-MgCa Alloy, Metals 8 (2018) 541, 15 pages. doi:10.3390/met8070541.

[24] R. Drevet, Y. Zhukova, P. Kadirov, S. Dubinskiy, A. Kazakbiev, Y. Pustov, S. Prokoshkin, Tunable corrosion behavior of calcium phosphate coated Fe-Mn-Si alloys for bone implant applications, Metall. Mater. Trans. A 49 (2018) 6553-6560. doi:10.1007/s11661-018-4907-6.

[25] W. Zhang, M. Li, Q. Chen, W. Hu, W. Zhang, W. Xin, Effects of Sr and Sn on microstructure and corrosion resistance of $\mathrm{Mg}-\mathrm{Zr}-\mathrm{Ca}$ magnesium alloy for biomedical applications, Mater. Design $39 \quad$ (2012) 379-383. doi:10.1016/j.matdes.2012.03.006.

[26] M. Răţoi, S. Stanciu, N. Cimpoeşu, I. Cimpoeşu, B. Constantin, C. Paraschiv, A potential biodegradable metallic material with shape memory effect based on iron, 
Adv. Mater. $\quad$ Res. $814 \quad$ 110-114. doi:10.4028/www.scientific.net/AMR.814.110.

[27] MATLAB and Statistics Toolbox Release 2012b, The MathWorks, Inc., Natick, MA, 2012.

[28] B. Yeum, Electrochemical Impedance Spectroscopy: Data Analysis Software, Echem Software, Ann Arbor, MI, 2001.

[29] ISO 10993-2:2006, Biological Evaluation of Medical Devices - Part 2: Animal Welfare Requirements, International Organization for Standardization, Geneve, 2006.

[30] M. Doube, M.M. Klosowski, I. Arganda-Carreras, F.P. Cordelières, R.P. Dougherty, J.S. Jackson, B. Schmid, J.R. Hutchinson, S.J. Shefelbine, BoneJ: Free and extensible bone image analysis in ImageJ, Bone 47 (2010) 1076-1079. doi:10.1016/j.bone.2010.08.023.

[31] IBM Corp. Released 2012 IBM SPSS Statistics for Windows, Version 21.0., IBM Corp., Armonk, NY, 2012.

[32] J.R. Macdonald, Note on the parameterization of the constant-phase admittance element, Solid State Ion. 13 (1984) 147-149. doi:10.1016/0167-2738(84)90049-3.

[33] F.E. Heakal, A.M. Fekry, A.A. Ghoneim, Corrosion characterization of new tinsilver binary alloys in nitric acid solutions, Corros. Sci. 50 (2008) 1618-1626. doi:10.1016 /j.corsci.2008.02.003/0167.

[34] C.P. Sousa, I.R. Dias, M. Lopez-Peña, J.A. Camassa, P.J. Lourenço, F.M. Judas, M.E. Gomes, R.L. Reis, Bone turnover markers for early detection of fracture healing disturbances: A review of the scientific literature, An. Acad. Bras. Cienc. 87 (2015) 1049-1061. doi:10.1590/0001-3765201520150008.

[35] S.A. Sheweita, K.I. Khoshhal, Calcium metabolism and oxidative stress in bone fractures: Role of antioxidants, Curr. Drug Metab. 8 (2007) 519-525. doi:10.2174/138920007780866852

[36] S. Khoshniat, A. Bourgine, M. Julien, P. Weiss, J. Guicheux, L. Beck, The emergence of phosphate as a specific signaling molecule in bone and other cell types in mammals, Cell. Mol. Life Sci. 68 (2011) 205-218. doi:10.1007/s00018-010-0527-z.

[37] S. Cremers, P. Garnero, M.J. Seibel, Biochemical markers of bone metabolism, in: 
Principles of Bone Biology, J.P. Bilezikian, L.G. Raisz, T.J. Martin (Eds.), $3^{\text {rd }}$. edn., Academic Press, San Diego, CA, 2008, pp. 1857-1881. doi:10.1016/B978-0-12373884-4.00020-3.

[38] G. Cox, T.A. Einhorn, C. Tzioupis, P. V. Giannoudis, Bone-turnover markers in fracture healing, J. Bone Joint Surg. Br. 92-B (2010) 329-334. doi:10.1302/0301620X.92B3.22787.

[39] O. Gamulin, K. Serec, V. Bilić, M. Balarin, M. Kosović, D. Drmić, L. Brčić, S. Seiwerth, P. Sikirić, Monitoring the healing process of rat bones using Raman spectroscopy, J. Mol. Struct. $1044 \quad$ (2013) 308-313. doi:10.1016/j.molstruc.2013.01.049

[40] M. Kumar, D. Shelke, S. Shah, Prognostic potential of markers of bone turnover in delayed-healing tibial diaphyseal fractures, Eur. J. Trauma Emerg. Surg. (2017). doi:10.1007/s00068-017-0879-2.

[41] J.A. Camassa, C.C. Diogo, C.P. Sousa, J.T. Azevedo, C.A. Viegas, R.L. Reis, N. Dourado, I.R. Dias, Bone turnover markers in sheep and goat: A review of the scientific literature, An. Acad. Bras. Cienc. 89 (2017) 231-245. doi:10.1590/00013765201720160407.

[42] B.-H. Yoon, W. Yu, Clinical utility of biochemical marker of bone turnover: fracture risk prediction and bone healing, J. Bone Metab. 25 (2018) 73-78. doi:10.11005/jbm.2018.25.2.73.

[43] M. Paskalev, N. Goranov, L. Sotirov, S. Krastev, R. Roydev, Effect of therapeutic ultrasound on bone healing and blood bone markers in dogs with experimental tibial osteotomies, Comp. Clin. Path. 21 (2012) 1593-1600. doi:10.1007/s00580-0111333-1.

[44] P.J. Harwood, D.O. Ferguson, (ii) An update on fracture healing and non-union, Orthop. Trauma 29 (2015) 228-242. doi:10.1016/j.mporth.2015.07.004.

[45] C. Sousa, F. Nery, J. Azevedo, C.. Viegas, M.. Gomes, I.. Dias, Tartrate-resistant acid phosphatase as a biomarker of bone turnover in dog, Arq. Bras. Med. Vet. Zootec. 63 (2011) 40-45. doi:10.1590/S0102-09352011000100007.

[46] P. Seebeck, H.J. Bail, C. Exner, H. Schell, R. Michel, H. Amthauer, H. Bragulla, G.N. Duda, Do serological tissue turnover markers represent callus formation during 
fracture healing?, Bone 37 (2005) 850-857. doi:10.1016/j.bone.2005.06.

[47] M.O. Coulibaly, D.L. Sietsema, T.A. Burgers, J. Mason, B.O. Williams, C.B. Jones, Recent advances in the use of serological bone formation markers to monitor callus development and fracture healing, Crit. Rev. Eukaryot. Gene Expr. 22 (2010) 629. doi:10.1016/j.bbi.2008.05.010.

[48] R. Marsell, T.A. Einhorn, The biology of fracture healing, Injury 42 (2011) 551-555. doi:10.1016/j.injury.2011.03.031.

[49] C.P. Sousa, M. Lopez-Peña, F.M. Guzón, H.V.D. Abreu, M.R. Luís, C.A. Viegas, J. Camassa, J.T.D. Azevedo, A.S. Cabrita, R.L. Reis, M.E. Gomes, I.R. Dias, Evaluation of bone turnover markers and serum minerals variations for predicting fracture healing versus non-union processes in adult sheep as a model for orthopedic research, Injury 48 (2017) 1768-1775. doi:10.1016/j.injury.2017.05.025.

[50] D. Stubbs, M. Deakin, P. Chapman-Sheath, W. Bruce, J. Debes, R.M. Gillies, W.R. Walsh, In vivo evaluation of resorbable bone graft substitutes in a rabbit tibial defect model, Biomaterials 25 (2004) 5037-5044. doi:10.1016/j.biomaterials.2004.02.014.

[51] M. Mapara, B.S. Thomas, K.M. Bhat, Rabbit as an animal model for experimental research, Dent. Res. J. 9 (2012) 111-118. doi: 10.4103/1735-3327.92960.

[52] Y. Li, S.K. Chen, L. Li, L. Qin, X.L. Wang, Y.X. Lai, Bone defect animal models for testing efficacy of bone substitute biomaterials, J. Orthop. Translat. 3 (2015) 95-104. doi:10.1016/j.jot.2015.05.002.

[53] X. Zhang, E.M. Schwarz, D.A. Young, J. Edward Puzas, R.N. Rosier, R.J. O’Keefe, Cyclooxygenase-2 regulates mesenchymal cell differentiation into the osteoblast lineage and is critically involved in bone repair, J. Clin. Invest. 109 (2002) 14051415. doi:10.1172/JCI0215681.

[54] Y. Hashimoto, G. Yoshida, H. Toyoda, K. Takaoka, Generation of tendon-to-bone interface "enthesis" with use of recombinant BMP-2 in a rabbit model, J. Orthop. Res. 25 (2007) 1415-1424. doi:10.1002/jor.20447.

[55] T.N. Vo, F.K. Kasper, A.G. Mikos, Strategies for controlled delivery of growth factors and cells for bone regeneration, Adv. Drug Deliv. Rev. 64 (2012) 1292-1309. doi:10.1016/j.addr.2012.01.016

[56] M.L. Bouxsein, S.K. Boyd, B.A. Christiansen, R.E. Guldberg, K.J. Jepsen, R. Müller, 
Guidelines for assessment of bone microstructure in rodents using micro-computed tomography, J. Bone Miner. Res. 25 (2010) 1468-1486. doi:10.1002/jbmr.141

[57] D.W. Dempster, J.E. Compston, M.K. Drezner, F.H. Glorieux, J.A. Kanis, H. Malluche, P.J. Meunier, S.M. Ott, R.R. Recker, A.M. Parfitt, Standardized nomenclature, symbols, and units for bone histomorphometry: A 2012 update of the report of the ASBMR Histomorphometry Nomenclature Committee, J. Bone Miner. Res. 28 (2013) 2-17. doi:10.1002/jbmr.1805.

[58] M.D. Zhao, J.S. Huang, X.C. Zhang, K.K. Gui, M. Xiong, W.P. Yin, F.L. Yuan, G.P. Cai, Construction of radial defect models in rabbits to determine the critical size defects, PLOS ONE $11 \quad$ (2016) e0146301, 15 pages. doi:10.1371/journal.pone.0146301.

[59] W.R. Walsh, F. Vizesi, D. Michael, J. Auld, A. Langdown, R. Oliver, Y. Yu, H. Irie, W. Bruce, $\beta$-TCP bone graft substitutes in a bilateral rabbit tibial defect model, Biomaterials 29 (2008) 266-271. doi:10.1016/j.biomaterials.2007.09.035.

[60] Z. Xu, M.A. Hodgson, P. Cao, Microstructure and degradation behavior of forged FeMnSi alloys, Int. J. Mod. Phys. B $29 \quad$ (2015) 1540014. doi:10.1142/S0217979215400147.

[61] Y.P. Feng, A. Blanquer, J. Fornell, H. Zhang, P. Solsona, M.D. Baró, S. Suriñach, E. Ibáñez, E. García-Lecina, X. Wei, R. Li, L. Barrios, E. Pellicer, C. Nogués, J. Sort, Novel Fe-Mn-Si-Pd alloys: Insights into mechanical, magnetic, corrosion resistance and biocompatibility performances, J. Mater. Chem. B. 4 (2016) 6402-6412. doi:10.1039/c6tb01951j.

[62] R. Drevet, Y. Zhukova, P. Malikova, S. Dubinskiy, A. Korotitskiy, Y. Pustov, S. Prokoshkin, Martensitic transformations and mechanical and corrosion properties of Fe-Mn-Si alloys for biodegradable medical implants, Metall. Mater. Trans. A 49 (2018) 1006-1013. doi:10.1007/s11661-017-4458-2.

[63] T. Sawaguchi, L.G. Bujoreanu, T. Kikuchi, K. Ogawa, M. Koyama, M. Murakami, Mechanism of reversible transformation-induced plasticity of Fe-Mn-Si shape memory alloys, Scr. Mater. $59 \quad$ (2008) 826-829. doi:10.1016/j.scriptamat.2008.06.030.

[64] B. Liu, Y.F. Zheng, L. Ruan, In vitro investigation of Fe30Mn6Si shape memory 
alloy as potential biodegradable metallic material, Mater. Lett. 65 (2011) 540-543. doi:10.1016/j.matlet.2010.10.068.

[65] Y.B. Ju, M. Koyama, T. Sawaguchi, K. Tsuzaki, H. Noguchi, In situ microscopic observations of low-cycle fatigue-crack propagation in high-Mn austenitic alloys with deformation-induced $\varepsilon$-martensitic transformation, Acta Mater. 112 (2016) 326336. doi:10.1016/j.actamat.2016.04.042.

[66] R. Crăciun, S. Stanciu, V. Geantă, I. Voiculescu, R. Cimpoeşu, V. Manole, F. Săndulache, N. Cimpoeşu, New FeMnSi+Al alloy proposed for high damping capacity elements, Mater. Sci. Forum 907 (2017) 61-66. https://doi.org/10.4028/www.scientific.net/MSF.907.61.
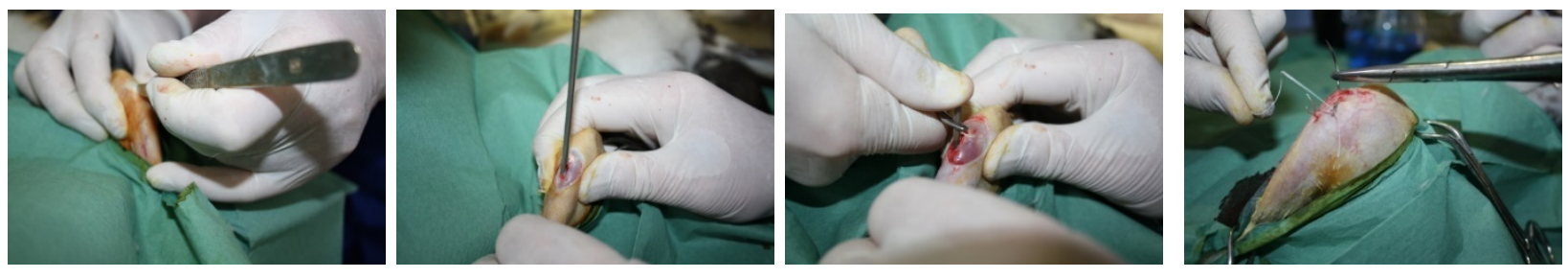

Figure 1. Main stages of the tibia implant surgery in a rabbit.

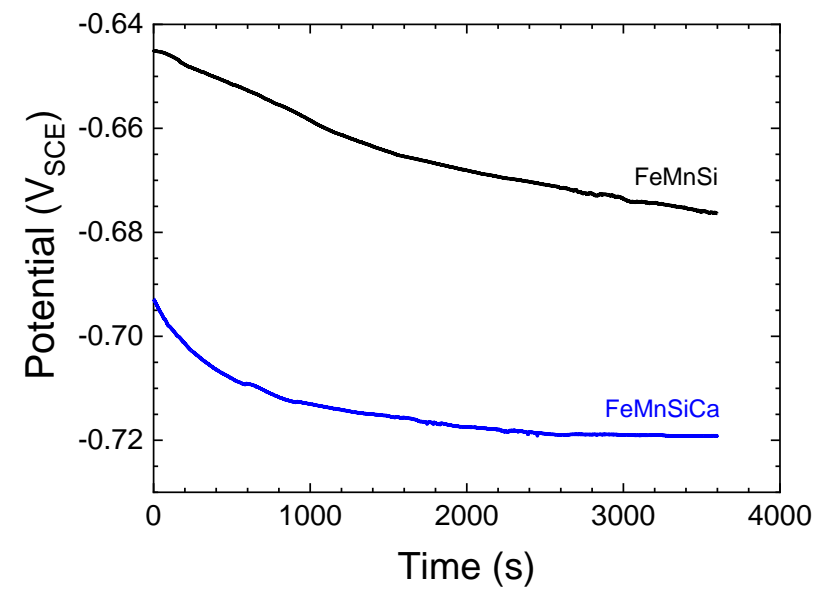

Figure 2. Initial time variation of the open circuit potential (OCP) for FeMnSi and FeMnSiCa alloys in Ringer's solution at $37^{\circ} \mathrm{C}$. 

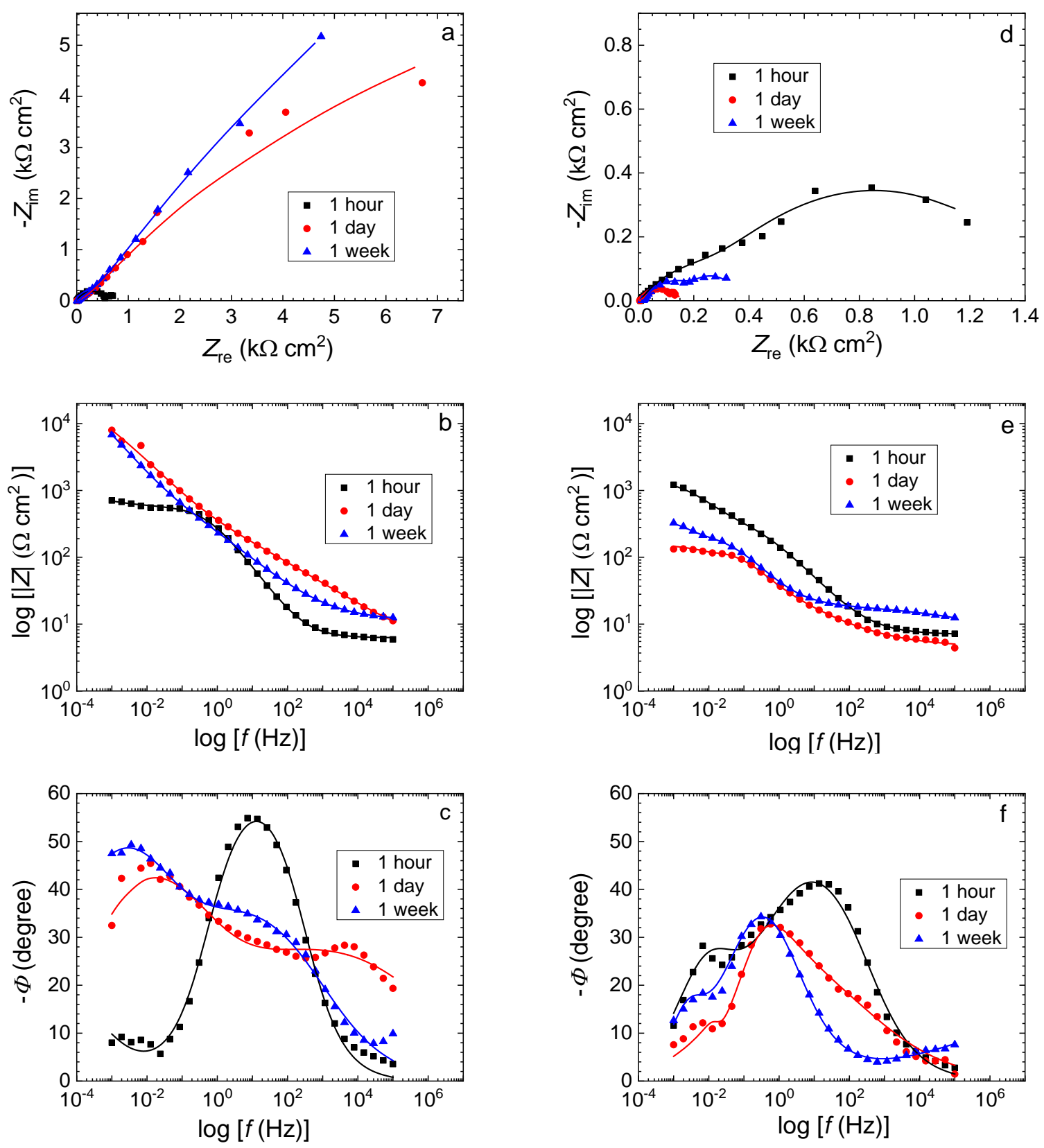

Figure 3. Nyquist plots (a,d) and Bode amplitude (b,e) and phase (c,f) plots recorded for (a-c) FeMnSi and (d-f) FeMnSiCa alloys after different immersion times in Ringer's solution at $37^{\circ} \mathrm{C}$, measured at their corresponding open circuit potential in the electrolyte. 

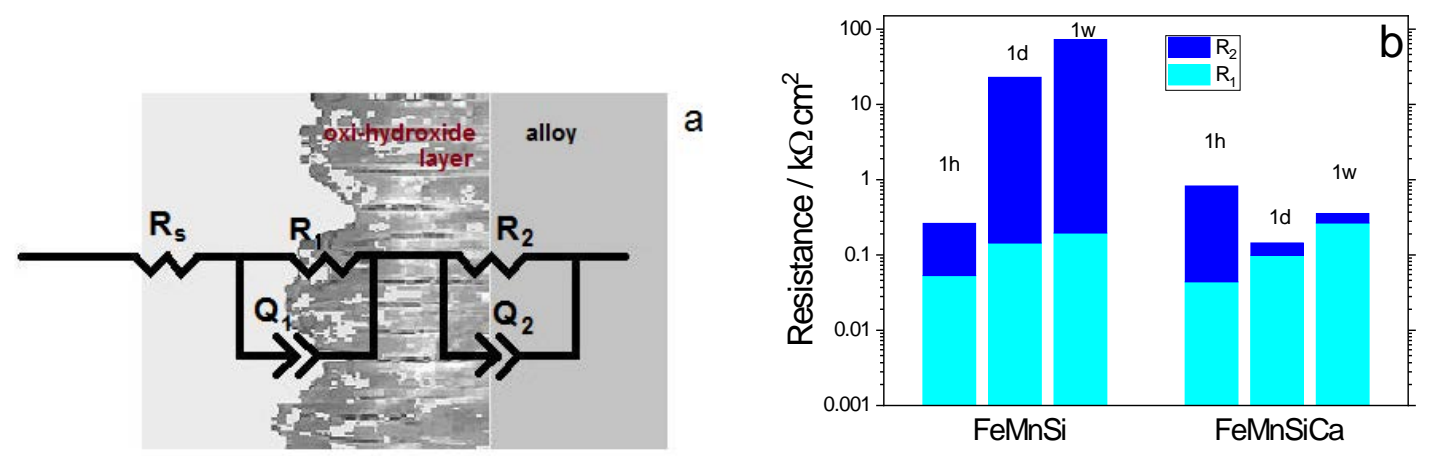

Figure 4. (a) Equivalent circuit (EC) used to fit the electrochemical impedance spectra. (b) Time evolution of the total resistance values derived from the fitted impedance data for FeMnSi and FeMnSiCa alloys immersed in Ringer's solution at $37^{\circ} \mathrm{C}$.

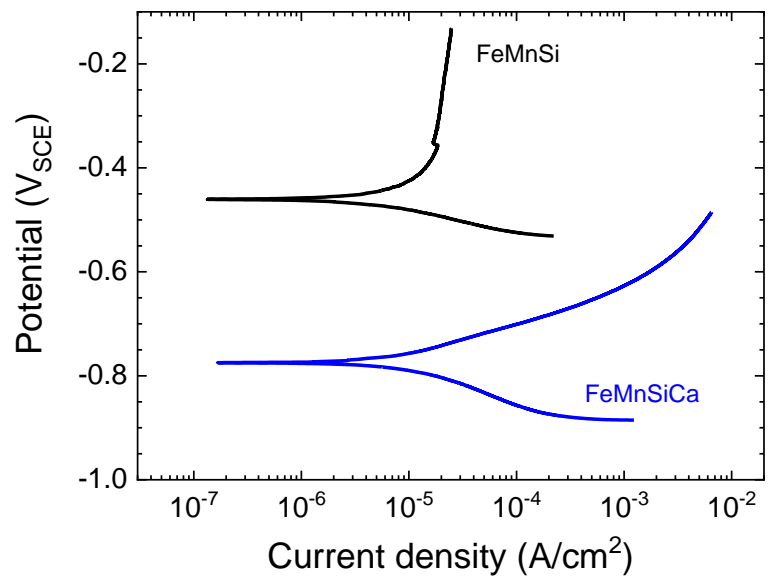

Figure 5. Lynear potentiodynamic polarization plots for FeMnSi and (d-f) FeMnSiCa alloys after 7-day immersion in Ringer's solution at $37^{\circ} \mathrm{C}$. Scan rate: $1 \mathrm{mV} / \mathrm{s}$. 

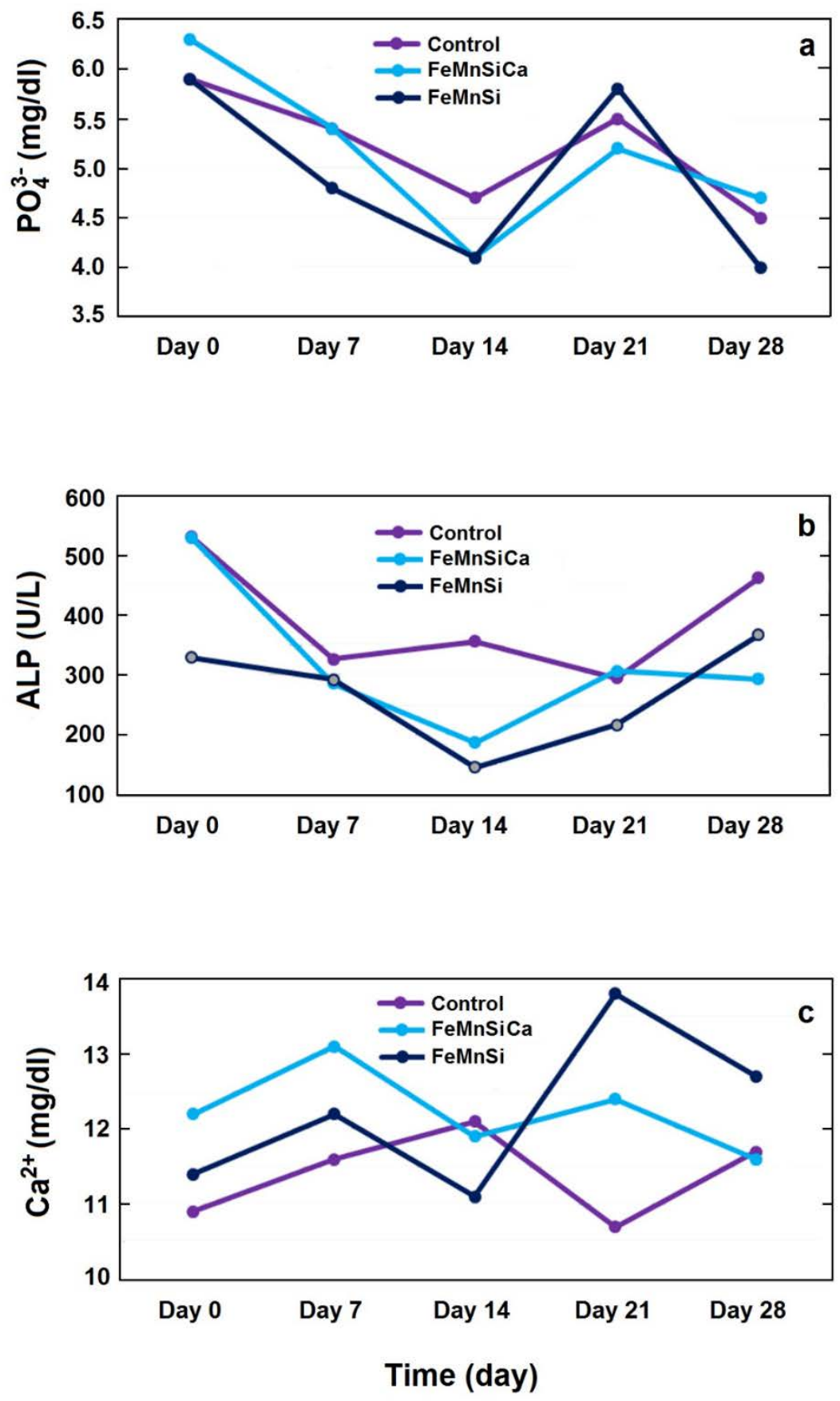

Figure 6. Dynamics of blood serum mean values of, (a) inorganic phosphate, (b) alkaline phosphatase activity, and (c) total calcium during the rabbit experimental model with tibial implant. 


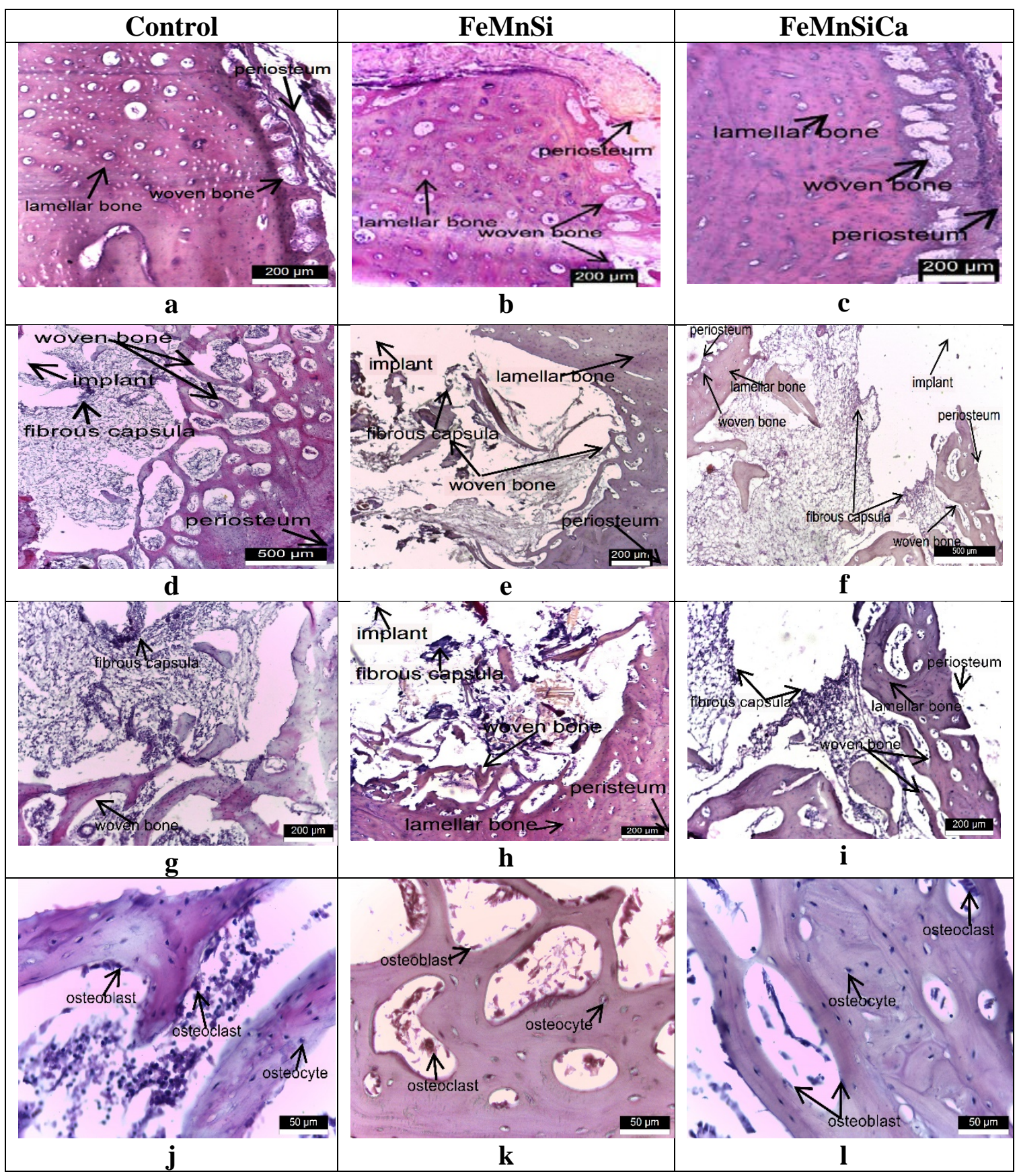

Figure 7. Morphology of bone tissue at the implant-bone interface of the three experimental rabbits groups (Control, FeMnSi and FeMnSiCa): a) after 2 weeks (first row) and b) after 4 weeks (second row) from implantation surgery with details presenting b1) new woven bone/lamellar bone ratio (third row) and predominance of the main cell types of bone tissue (fourth row). Coloration HE $\times 500, \times 200, \times 50$. 


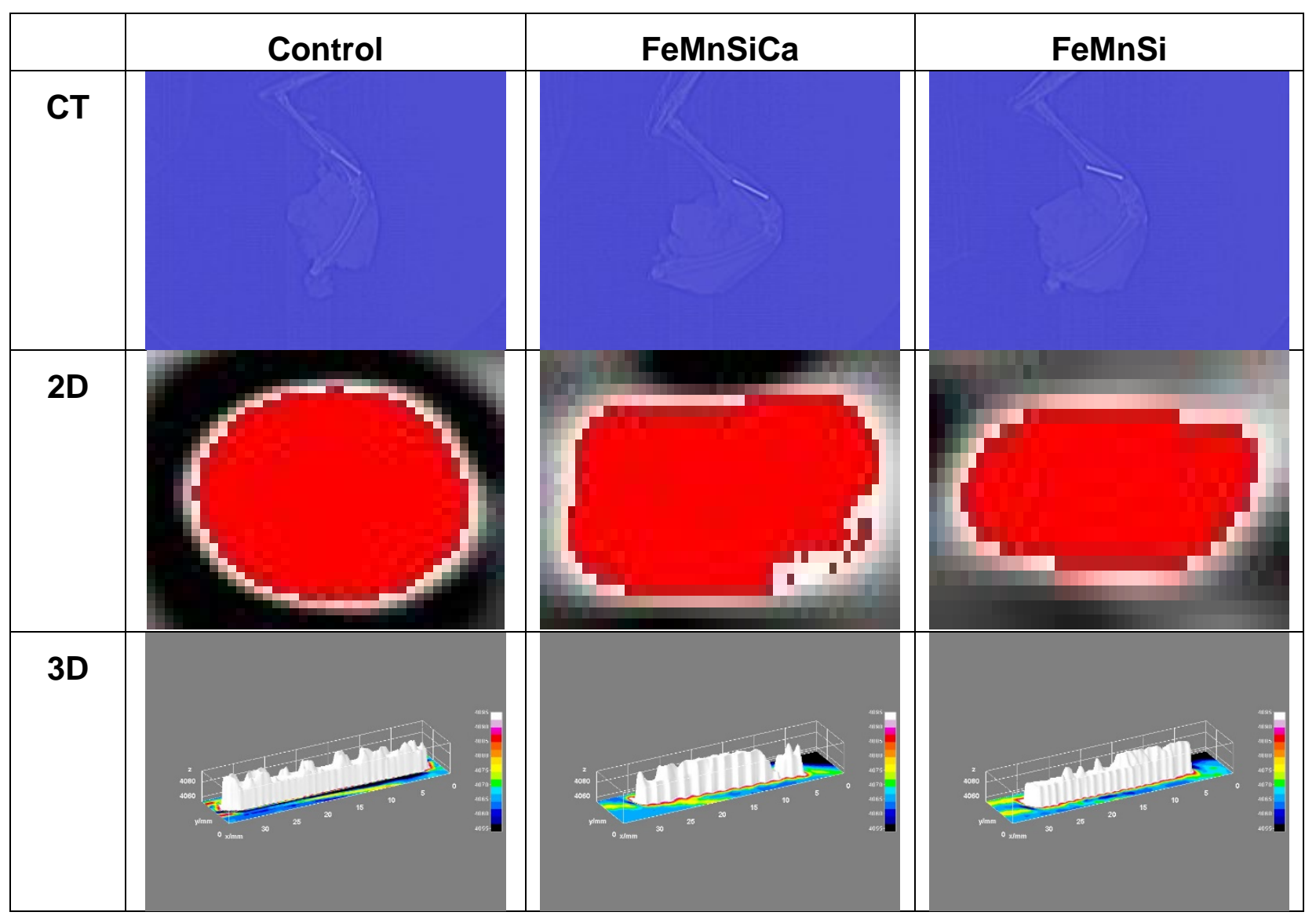

Figure 8. CT, 2D reconstructive (transversal section) and 3D reconstructive images of the implanted specimens in rabbit tibia. 

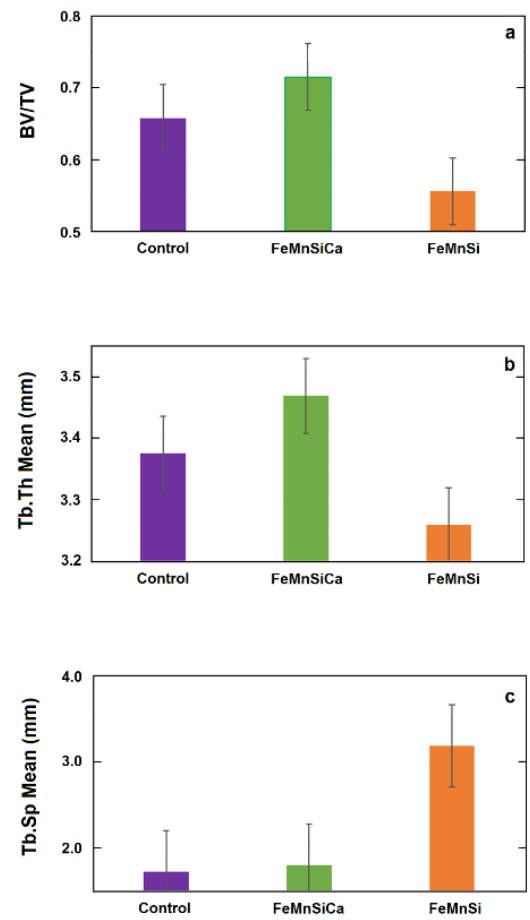

Figure 9. Evolution of BV/TV, Tb.Th, and Tb.Sp mean values in rabbit tibia. Data were determined by defining a rectangular region at $1 \mathrm{~mm}$ distance (both in length and width) from the implant surface.
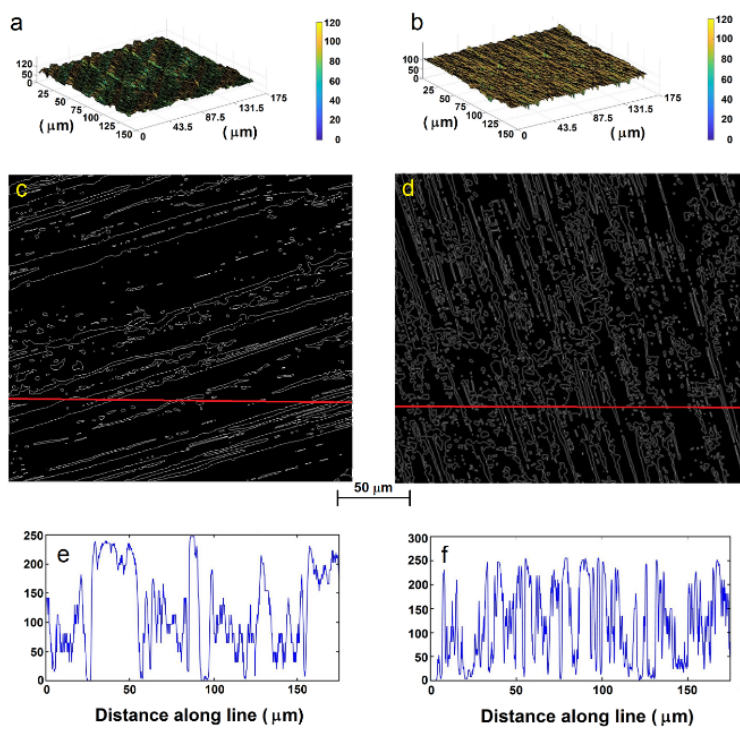

Figure 10. Surface topography analysis by SEM micrographs of the (a,c,e) FeMnSi and (b,d,f) FeMnSiCa specimens after implantation and following subsequent ultrasonic cleaning. 
Table 1. Electrochemical parameters obtained from EIS data measured for FeMnSi and FeMnSiCa samples during immersion in Ringer's solution at $37^{\circ} \mathrm{C}$. The meaning of the electrochemical parameters is given by the equivalent circuit shown in Figure 4a.

\begin{tabular}{|c|c|c|c|c|c|c|c|c|}
\hline Material & $\begin{array}{c}\text { Exposure } \\
\text { time }\end{array}$ & $\begin{array}{l}R_{\mathrm{S}}(\Omega \\
\left.\mathbf{c m}^{2}\right)\end{array}$ & $\begin{array}{r}R_{1}(\Omega \\
\left.\mathbf{c m}^{2}\right)\end{array}$ & $\begin{array}{c}Q_{1}\left(\mathrm{mS} / \mathrm{cm}^{2}\right. \\
\left.\mathrm{s}^{n}\right)\end{array}$ & $n_{1}$ & $\begin{array}{c}R_{2}(\mathrm{k} \Omega \\
\left.\mathbf{c m}^{2}\right)\end{array}$ & $\begin{array}{c}Q_{2}\left(\mathrm{mS} / \mathrm{cm}^{2}\right. \\
\left.\mathrm{s}^{n}\right)\end{array}$ & $n_{2}$ \\
\hline \multirow{3}{*}{ FeMnSi } & 1 hour & 6.66 & 53.2 & 0.651 & 0.74 & 0.209 & 254 & 1 \\
\hline & 1 day & 13.2 & 144 & 0.152 & 0.60 & 22.7 & 1.60 & 0.56 \\
\hline & 1 week & 15.4 & 195 & 0.438 & 0.67 & 72.7 & 2.84 & 0.59 \\
\hline \multirow{3}{*}{ FeMnSiCa } & 1 hour & 7.25 & 43.8 & 1.70 & 0.60 & 0.780 & 51.9 & 1 \\
\hline & 1 day & 6.24 & 98.7 & 7.42 & 0.55 & 0.099 & 508 & 1 \\
\hline & 1 week & 16.2 & 265 & 10.1 & 0.58 & 0.090 & 1026 & 1 \\
\hline
\end{tabular}

Table 2. Electrochemical parameters determined from linear potentiodynamic polarization tests for FeMnSi and FeMnSiCa samples immersed for 7 days in Ringer's solution at 37 ${ }^{\circ} \mathrm{C}$.

\begin{tabular}{|c|c|c|}
\hline Material & OCP $\left(\mathbf{V}_{\text {sCE }}\right)$ & $\boldsymbol{j}_{\mathbf{c o r}}\left(\mathbf{m A} / \mathbf{c m}^{\mathbf{2}}\right)$ \\
\hline FeMnSi & -0.462 & 3.37 \\
\hline FeMnSiCa & -0.773 & 8.44 \\
\hline
\end{tabular}


Table 3. New woven bone structural parameters according to BoneJ histomorphometry of H\&E stained histological samples from rabbit's tibia at 2 and 4 weeks postimplantation.

\begin{tabular}{|l|c|c|c|c|c|c|}
\hline \multirow{4}{*}{ Parameter } & \multicolumn{6}{|c|}{ Group } \\
\cline { 2 - 7 } & \multicolumn{2}{|c|}{ Control } & \multicolumn{2}{c|}{ FeMnSi } & \multicolumn{2}{c|}{ FeMnSiCa } \\
\cline { 2 - 7 } & $\begin{array}{c}\text { @ 2weeks } \\
\text { post- } \\
\text { implantation }\end{array}$ & $\begin{array}{c}\text { @ 4 weeks } \\
\text { post- } \\
\text { implantation }\end{array}$ & $\begin{array}{c}\text { @ 2weeks } \\
\text { post- } \\
\text { implantation }\end{array}$ & $\begin{array}{c}\text { @ 4 weeks } \\
\text { post- } \\
\text { implantation }\end{array}$ & $\begin{array}{c}\text { @ 2 weeks } \\
\text { post- } \\
\text { implantation }\end{array}$ & $\begin{array}{c}\text { @ 4 weeks } \\
\text { post- } \\
\text { implantation }\end{array}$ \\
\hline $\begin{array}{l}\text { BV/TV } \\
(\%)\end{array}$ & $30.05 \pm 4.65$ & $46.15 \pm 5.12$ & $39.42 \pm 3.19$ & $49.97 \pm 4.72$ & $54.82 \pm 5.79 *$ & $68.12 \pm 6.81^{*}$ \\
\hline $\begin{array}{l}\text { Tb.Th } \\
(\mu \mathrm{m})\end{array}$ & $23.63 \pm 3.23$ & $28.97 \pm 3.73$ & $24.77 \pm 3.43$ & $30.37 \pm 4.16$ & $27.96 \pm 3.05$ & $37.35 \pm 3.63 *$ \\
\hline $\begin{array}{l}\text { Tb. Sp } \\
(\mu \mathrm{m})\end{array}$ & $25.55 \pm 3.53$ & $21.12 \pm 3.25$ & $21.25 \pm 2.63$ & $17.12 \pm 2.03$ & $17.54 \pm 1.64 *$ & $13.33 \pm 1.65 *$ \\
\hline
\end{tabular}

* Statistically significant difference $(p<0.05)$ when compared with the control group $(n=27)$

Table 4. Surface topography characterization of the samples removed animal testing for 28 days and subsequent cleaning.

\begin{tabular}{|c|c|c|c|}
\hline Material & $\begin{array}{c}\text { Specific surface of } \\
\text { pores (3D) }\end{array}$ & Porosity (\%) & $\begin{array}{c}\text { Average roughness, } \boldsymbol{R}_{\mathbf{a}} \\
\mathbf{( \boldsymbol { \mu m } )}\end{array}$ \\
\hline FeMnSi & 0.014 & 0.601 & 6.801 \\
\hline FeMnSiCa & 0.028 & 0.758 & 4.944 \\
\hline
\end{tabular}


Table 5. Surface composition by EDS from a FeMnSi specimen after implantation (areas 1-3), and after implantation and cleaning (areas 4-6). See the text for details.

\begin{tabular}{|c|c|c|c|c|c|c|c|c|c|}
\hline \multirow{2}{*}{$\begin{array}{l}\text { FeMnSi } \\
\text { alloy }\end{array}$} & \multicolumn{9}{|c|}{ Element } \\
\hline & $\begin{array}{c}\text { Fe } \\
\text { (wt. \%) }\end{array}$ & $\begin{array}{c}\text { Mn } \\
\text { (wt. \%) }\end{array}$ & $\begin{array}{c}\text { Si } \\
\text { (wt.\%) }\end{array}$ & $\begin{array}{c}\text { O } \\
\text { (wt. \%) }\end{array}$ & $\begin{array}{c}\text { Ca } \\
(w t . \%)\end{array}$ & $\begin{array}{c}\text { P } \\
\text { (wt.\%) }\end{array}$ & $\begin{array}{c}\text { K } \\
\text { (wt. \%) }\end{array}$ & $\begin{array}{c}\text { S } \\
(w t . \%)\end{array}$ & $\begin{array}{c}\text { C } \\
(\text { wt. \%) }\end{array}$ \\
\hline Area 1 & 41.00 & 0.34 & 0.66 & 10.54 & 7.14 & 9.89 & 1.21 & 1.63 & 27.59 \\
\hline Area 2 & 27.96 & 0.25 & 0.54 & 18.07 & 13.88 & 12.82 & 1.42 & 1.78 & 23.28 \\
\hline Area 3 & 44.28 & 0.35 & 0.73 & 10.77 & 9.32 & 10.63 & 1.52 & 1.58 & 20.83 \\
\hline Area 4 & 85.97 & 10.53 & 1.29 & 2.21 & - & - & - & - & - \\
\hline Area 5 & 83.98 & 12.55 & 1.06 & 2.41 & - & - & - & - & - \\
\hline Area 6 & 82.74 & 13.67 & 1.25 & 2.34 & - & - & - & - & - \\
\hline
\end{tabular}

Standard deviations: Fe: \pm 1.1 ; $\mathrm{Mn}: \pm 0.22$; Si: \pm 0.3 ; $\mathrm{Mg}: \pm 0.1$; Ca: \pm 0.05

Table 6. Surface composition by EDS from a FeMnSiCa specimen after implantation (areas 1-3), and after implantation and cleaning (areas 4-6). See the text for details.

\begin{tabular}{|c|c|c|c|c|c|c|c|c|c|}
\hline \multirow{2}{*}{$\begin{array}{l}\text { FeMnSiCa } \\
\text { alloy }\end{array}$} & \multicolumn{9}{|c|}{ Element } \\
\hline & $\begin{array}{c}\text { Fe } \\
\text { (wt. \%) }\end{array}$ & $\begin{array}{c}\text { Mn } \\
\text { (wt. \%) }\end{array}$ & $\begin{array}{c}\text { Si } \\
\text { (wt. \%) }\end{array}$ & $\begin{array}{c}\text { O } \\
(w t . \%)\end{array}$ & $\begin{array}{c}\text { Ca } \\
\text { (wt. \%) }\end{array}$ & $\begin{array}{c}\text { P } \\
(w t . \%)\end{array}$ & $\begin{array}{c}\text { K } \\
\text { (wt. \%) }\end{array}$ & $\begin{array}{c}\text { S } \\
\text { (wt. \%) }\end{array}$ & $\begin{array}{c}\text { C } \\
\text { (wt. \%) }\end{array}$ \\
\hline Area 1 & 29.79 & 2.36 & 0.12 & 14.68 & 6.86 & 9.82 & 1.14 & - & 35.23 \\
\hline Area 2 & 30.71 & 1.92 & 0.08 & 14.59 & 6.16 & 7.76 & 1.30 & 1.66 & 35.83 \\
\hline Area 3 & 52.18 & 5.55 & 1.42 & 7.69 & 4.82 & 7.26 & 0.76 & 1.22 & 19.11 \\
\hline Area 4 & 83.27 & 10.77 & 3.58 & 2.37 & - & - & - & - & - \\
\hline Area 5 & 81.78 & 12.70 & 3.39 & 2.13 & - & - & - & - & - \\
\hline Area 6 & 81.01 & 13.37 & 3.40 & 2.21 & - & - & - & - & - \\
\hline
\end{tabular}

Standard deviations: Fe: \pm 1.1 ; Mn: \pm 0.22 ; Si: \pm 0.3 ; Mg: \pm 0.1 ; Ca: \pm 0.05 